\title{
Clinical trial of topical insulin and sodium hyaluronate in the treatment of epithelial defects produced by intraoperative corneal epithelial debridement during pars plana vitrectomy in diabetics
}

\section{Ensayo clínico de insulina tópica y hialuronato sódico en el tratamiento del defecto epitelial producido por el desbridamiento corneal transquirúrgico durante la vitrectomía vía pars plana en diabéticos}

\author{
Jaime L. Quiroz-Mendoza*, Marlon García-Roa, Verónica Romero-Morales, Diego Valera-Cornejo, \\ Miguel Vázquez-Membrillo, Paulina Ramírez-Neria, Yolanda Villalpando-Gómez, and Renata García-Franco
}

Retina and Vitreous Department, Instituto Mexicano de Oftalmología, Private Assistance Institution, Santiago de Querétaro, Querétaro, Mexico

\begin{abstract}
Purpose: To compare the effect of topical insulin and sodium hyaluronate in the treatment of epithelial defects secondary to intraoperative corneal epithelial debridement during pars plana vitrectomy in diabetics. Methods: Controlled clinical trial. Patients were randomized to one of three treatment groups: topical $0.15 \%$ sodium hyaluronate (group I), topical insulin 0.5 IU/drop (group II) or combined treatment with topical insulin 0.5 IU/drop and $0.15 \%$ sodium hyaluronate (group III). Results: Thirty-six eyes of 36 patients were included, 12 eyes in each group. There were no statistically significant differences in baseline characteristics. The time required until complete re-epithelialization was of $4.25 \pm 0.62,3.0 \pm 0.85$ and $3.33 \pm$ 0.98 days, in groups I, II and III, respectively; group II showed a significantly shorter reepithelialization time $(p<0.001)$. All groups had a reduction in the area of the epithelial defect from day 1; a smaller area was observed in group II; however, this difference was not statistically significant. No adverse effects were reported. Conclusions: Both topical insulin and combined treatment with topical insulin and sodium hyaluronate are effective to treat corneal epithelial defects secondary to intraoperative corneal epithelial debridement during pars plana vitrectomy in diabetics. The addition of sodium hyaluronate to topical insulin did not provide a greater benefit. The three treatments were safe and well tolerated.
\end{abstract}

Key words: Diabetes mellitus. Corneal epithelium. Sodium hyaluronate. Insulin. Diabetic retinopathy. Vitrectomy.

\section{Resumen}

Objetivo: Comparar el efecto de la insulina tópica y del hialuronato sódico en el cierre del defecto epitelial producido por el desbridamiento corneal transquirúrgico durante la vitrectomía vía pars plana en diabéticos. Método: Ensayo clínico controlado. Los pacientes fueron aleatorizados a uno de tres grupos de tratamiento: hialuronato sódico tópico al $0.15 \%$ (grupo

Correspondence:

*Jaime L. Quiroz-Mendoza

Av. Estadio, s/n

Col. Colinas de Cimatario, Centro Sur Date of reception: 11-03-2020

76090 Santiago de Querétaro, Querétaro, Mexico

E-mail: james_hp10@hotmail.com

Date of acceptance: $29-09-2020$

DOI: 10.24875/RMOE.M21000157
Available online: $16-03-2021$

Rev Mex Oftalmol (Eng). 2021;95(2):60-67

www.rmo.com.mx

2604-1731/@ 2020 Sociedad Mexicana de Oftalmología. Published by Permanyer. This is an open access article under the CC BY-NC-ND license (http://creativecommons.org/licenses/by-nc-nd/4.0/). 
I), insulina tópica $0.5 \mathrm{UIIgota} \mathrm{(grupo} \mathrm{II)} \mathrm{o} \mathrm{tratamiento} \mathrm{combinado} \mathrm{con} \mathrm{insulina} 0.5 \mathrm{Ul} /$ gota y hialuronato sódico tópicos al 0.15\% (grupo III). Resultados: Se incluyeron 36 ojos de 36 pacientes, 12 ojos en cada grupo. No hubo diferencias estadísticamente significativas en las características basales. El tiempo necesario hasta la reepitelización completa fue de $4.25 \pm$ $0.62,3.0 \pm 0.85$ y $3.33 \pm 0.98$ días en los grupos I, II y III, respectivamente, presentado el grupo II un tiempo de reepitelización significativamente menor $(p<0.001)$. En todos los grupos se redujo el área del defecto epitelial a partir del día 1, con una menor área en el grupo II; sin embargo, esta diferencia no fue estadísticamente significativa en comparación con los otros grupos. No se reportaron efectos adversos. Conclusiones: La insulina tópica y el tratamiento combinado de insulina tópica y hialuronato sódico son efectivos para el cierre de defectos epiteliales después del desbridamiento corneal transquirúrgico en diabéticos. La insulina tópica y el tratamiento combinado de esta con hialuronato sódico tienen un mayor efecto que el tratamiento solo con hialuronato sódico. El tratamiento con insulina y el tratamiento combinado demostraron ser seguros y bien tolerados.

Palabras clave: Diabetes mellitus. Epitelio corneal. Hialuronato sódico. Insulina. Retinopatía diabética. Vitrectomía.

\section{Introduction}

Pars plana vitrectomy in diabetic patients has a high rate of corneal complications, including epithelial defects and stromal edema, which often are resistant to conventional treatment ${ }^{1}$. The influence of systemic conditions (hemoglobin A1c values, diabetic neuropathy or nephropathy) in their occurrence is not well established yet ${ }^{1}$.

Diabetes mellitus is a risk factor for persistent corneal epithelial defects after vitrectomy ${ }^{2}$, which can cause infectious keratitis, endophthalmitis, scarring, lysis or corneal perforation, generating discomfort, delayed visual recovery and even visual loss regardless of the vitreoretinal diagnosis for which the vitrectomy was performed $^{3}$. The pathophysiologic mechanism of corneal epithelial defects in diabetics include changes in the composition of the epithelial basement membrane, deposits of glycation products, damage to corneal nerve endings, reduction in tear secretion, and oxidative stress under hyperglycemic conditions ${ }^{4}$; also, higher levels of matrix metalloproteinases-10 were reported in patients with diabetes with corneal epithelial changes after vitrectomy ${ }^{5}$.

In $17.4 \%$ of pars plana vitrectomies in diabetics, corneal debridement is necessary to improve surgeons' visibility when the cornea has become edematous, especially during a complex or prolonged surgery ${ }^{6,7}$.

Zagon, et al. ${ }^{8}$ reported the beneficial effect of topical insulin for closure of induced corneal epithelial defects in diabetic rats, with no effect in non-diabetic rats or on blood glucose and intraocular pressure. Subsequent studies in human volunteers showed that topical insulin diluted in saline at doses up to $100 \mathrm{IU} / \mathrm{mL}$ did not show signs of ocular toxicity or systemic absorption, and did not induce changes in blood glucose values ${ }^{9,10}$. Wang, et al. ${ }^{11}$ showed a positive effect of topical insulin in the treatment of neurotrophic corneal ulcers refractory to conventional treatment. Bastion and Ling ${ }^{12}$ reported an improvement in corneal epithelial defects after vitrectomy when using topical insulin $1 \mathrm{IU} /$ drop on diabetics, without statistically significant differences when compared with the eyes of non-diabetic patients. Fai, et al. ${ }^{7}$ corroborated these findings in a randomized clinical trial with various doses of topical insulin, demonstrating the superiority of the dose of $0.5 \mathrm{IU} / \mathrm{drop}$, with $100 \%$ healing 72 hours after starting treatment.

The objective of this study was to compare the effect of insulin, sodium hyaluronate, and combined treatment on the time to achieve complete closure of the epithelial defect produced by intraoperative corneal debridement during a pars plana vitrectomy in diabetics.

\section{Methods}

\section{Study design}

This was a controlled clinical trial carried out in diabetic patients from the Retina and Vitreous Department of the Instituto Mexicano de Oftalmología I.A.P., in Querétaro, Mexico. The study data were collected from August 2019 to February 2020, in compliance with the Declaration of Helsinki and after approval by the Research Ethics Committee of the Instituto Mexicano de Oftalmología I.A.P. (CONBIOETICA registry 22-CEI-003-2016215, number CEI/020-2/2019). All participants gave their written informed consent prior to the procedure.

\section{Inclusion criteria and follow-up}

Eligibility criteria included the eyes of patients with a diagnosis of type 1 or 2 diabetes mellitus, older than 18 years, who underwent a pars plana vitrectomy for any diagnosis and in whom intraoperative corneal 
debridement was necessary. Epithelial debridement was only performed when there was intraoperative corneal epithelial edema that produced corneal opacity and limited visibility during surgery. Patients with previous ocular surface disease (severe dry eye, limbal cell deficiency or a history of chemical ocular trauma), antiglaucoma drug users, and contact lens wearers were excluded. Patients who abandoned treatment or decided to withdraw from the study, those who did not complete the follow-up controls, those who developed endophthalmitis after the procedure, and those who required any surgical reintervention during the follow-up period were excluded from the study. The severity of dry eye was determined by reviewing the clinical history that included the OSDI (Ocular Surface Disease Index), defining a final score of $>33$ as severe disease.

On day 0 (after surgery) the baseline corneal epithelial defect was recorded using topical fluorescein staining in the conjunctival cul-de-sac of the operated eye, and clinical photographs were taken with an anterior segment camera (Color Camera HV-D30, Hitachi Kokusai Electric, Japan) adapted to the slit lamp under cobalt blue light illumination. The clinical evaluation of the epithelial defect and the photographs were repeated every 24 hours until the closure of the epithelial defect.

\section{Randomization}

Participants' eyes were randomized in a 1:1:1 ratio to be treated with topical sodium hyaluronate $0.15 \%$ (group I), 0.5 IU topical insulin (group II), or combined treatment with $0.5 \mathrm{IU}$ topical insulin and topical sodium hyaluronate $0.15 \%$ (group III). Only one eye per patient was included in the study and this was selected considering the inclusion criteria. A placebo group was not considered for ethical considerations. The eyes of the enrolled patients were randomly assigned to one of the three study groups using a computer-generated system (random.org), which was performed by one of the investigators (JQM) through the option "true random number generator", configured to randomly generate a number from 1 to 3 to include the participant in one of the three groups. This was done until the groups completed the sample size; the selection focused on the remaining groups if any group completed its size earlier. The randomization process was carried out on the day the patient started treatment. The type of intervention was determined using this method and the patients were randomized after obtaining their consent and before starting the postoperative treatment. Once designated to one of the three groups, they were not allowed to change groups at any point in the study. The patients were masked for the treatment, but not the investigator (JQM). Another investigator (DVC) prepared the topical insulin according to a written protocol. Participants were given a white, unlabeled eye dropper containing the same volume of topical insulin or sodium hyaluronate for groups I and II, respectively; patients in the combined treatment group were given two white vials, one containing insulin and the other sodium hyaluronate, with a label attached indicating their frequency of use. All the vitrectomies were performed by expert surgeons, who did not have a selection or randomization process. The EiBOS 2 non-contact visualization system (Haag Streit, USA) was used for all vitreoretinal surgeries.

\section{Intervention}

All patients received a similar postsurgical regimen of topical steroids (prednisolone acetate $1 \%$ ) every 4 hours and a topical antibiotic every 4 hours (gatifloxacin $0.3 \%$ ) in the operated eye, which was gradually reduced after 1 week. In addition to this, insulin, sodium hyaluronate or the combined treatment was used.

\section{Active intervention: insulin and combined treatment}

Insulin at a dose of $0.5 \mathrm{IU} / \mathrm{drop}$ was prepared under aseptic conditions using $100 \mathrm{IU} / \mathrm{mL}$ recombinant human insulin (Humulin ${ }^{\circledR}$ R, Eli Lilly and Company, Indiana, USA). We took $1.25 \mathrm{~mL}$ of insulin (125 IU) in a sterile unlabeled eye drop container and added $3.75 \mathrm{~mL}$ of sterile $0.9 \%$ saline, for a final concentration of $25 \mathrm{IU} / \mathrm{mL}$, equivalent to $0.5 \mathrm{IU} / \mathrm{drop}^{7}$. The patients instillated one drop 4 times a day, at a dose of $0.5 \mathrm{IU} / \mathrm{drop}$ of topical insulin, in addition to postoperative treatment. Patients were instructed to keep the bottle refrigerated and it was changed for a new one when the duration of the treatment was greater than 3 days. The insulin drops were discontinued once the corneal epithelial defect had completely closed. No verification technique was performed to corroborate adherence to treatment, which was verified by verbal confirmation.

In the case of the combined treatment, the compounds were administered in separate white bottles, each with a label indicating the frequency of use (insulin "one drop 4 times/day" and hyaluronate "one drop 6 times/day"), and patients were instructed to wait at least 15 minutes between the topical instillation of each compound when both coincided; it was also explained 
that the instillation should be done with the lower eyelid pulled down to facilitate the procedure. The drops were suspended when the corneal epithelial defect closed completely.

\section{Control intervention: sodium hyaluronate}

The patients received, in addition to the postoperative treatment described, one drop 6 times a day of $0.15 \%$ topical sodium hyaluronate $\left(\right.$ Hyabak $^{\circledR}$, Théa ${ }^{\circledR}$ Laboratories México), which was provided in an unlabeled white bottle. The drops were discontinued once the corneal epithelial defect achieved complete closure.

\section{Sample size}

A value of $\alpha=0.05$ and a power of $80 \%$ was considered. Using as reference previous data from a study about re-epithelialization rate $\left(\mathrm{mm}^{2} / \mathrm{h}\right)^{8}$, with which a sample size of 9.73 was determined, that is, a minimum of 10 patients for each comparison group using sample size estimation for means comparison. In addition, an adjustment for possible losses was considered using the formula [loss-adjusted sample $=n(1 / 1-R)]$, where $n$ is the number of subjects without losses and $R$ is the expected proportion of losses. In the present study, a $15 \%$ loss was expected, so the estimated sample size was of $9.73(1 / 1-0.15)=11.44$ (12 patients in each group).

\section{Image analysis}

A single investigator (JQM) analyzed all the images, manually delineating the epithelial defect in fluorescein-stained anterior segment photographs using the $\mathrm{Im}$ ageJ image analysis program, a public domain digital image processing program developed at the National Institutes of Health (Fig. 1). This program allows to scale the image at a selected distance and convert the pixels of the selected distance to the desired unit, thus calculating a preset unit. For the study, a horizontal line was marked on the computer from the nasal limbus of the cornea to the opposite temporal limbus in the maximum horizontal corneal diameter, allowing the pixels of the selected distance to be correlated to millimeters (the horizontal corneal diameter in millimeters was measured with a slit lamp for each patient). Subsequently, the epithelial defect was delineated to calculate its area in square millimeters. Re-epithelialization was defined as the baseline epithelial defect minus the current defect divided by the baseline defect multiplied by 100 .

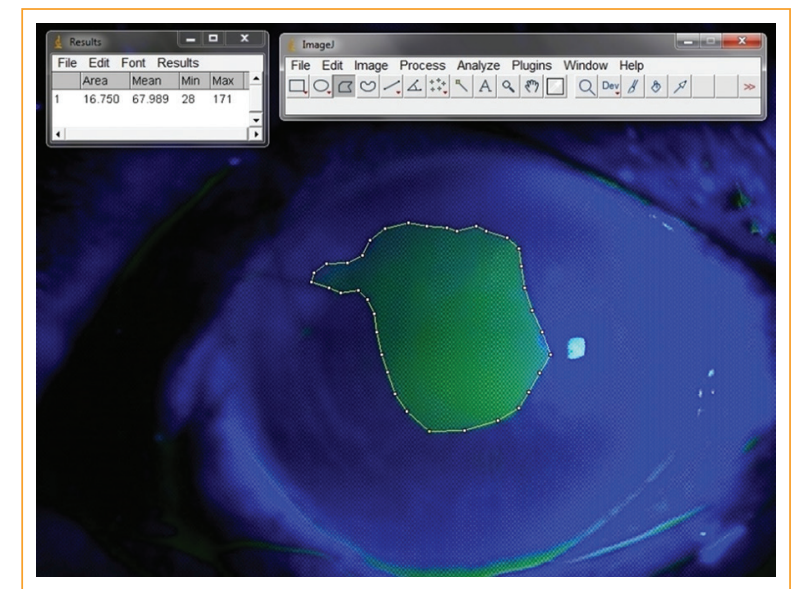

Figure 1. Calculation of the area $\left(\mathrm{mm}^{2}\right)$ of the epithelial defect using the ImageJ program.

\section{Primary outcome}

The main objective was to evaluate the time (days) until the closure of the corneal epithelial defect in all groups. Closure of the epithelial defect was defined as the $a b-$ sence of any corneal lesions after topical instillation of fluorescein or the presence of isolated minimal residual fluorescein staining with little or no symptoms. The secondary objectives were to measure the area of the corneal epithelial defect and to determine the rate of corneal re-epithelialization and the percentage of daily reduction of the epithelial defect area, in addition to the occurrence of adverse events such as persistence of the epithelial defect, infection, corneal lysis or corneal perforation.

\section{Statistics}

Descriptive statistics were performed, presenting the variables with summary measures of central tendency and dispersion for the quantitative variables, and with absolute and relative frequencies for the qualitative variables. The normality of the quantitative variables was evaluated with the Shapiro-Wilk test, with a significance level of 0.05. Chi-square and Kruskal-Wallis tests were used for inferential statistics with the statistical package Stata ${ }^{\circledR}$ version 15.1 (StataCorp. 2015, Stata Statistical Software: Release 15. College Station, Texas, US: StataCorp LP.), with a significance level of 0.05 .

\section{Results}

Thirty-six eyes of 36 diabetic patients who underwent debridement of the corneal epithelium during a pars plana 
Table 1. Baseline demographic and clinical characteristics $(n=36)$

\begin{tabular}{|c|c|c|c|c|}
\hline Variable & Group I ( $=12$ ) & Group II (n= 12) & Group III ( $n=12)$ & $\mathbf{p}^{*}$ \\
\hline Age in years, median (IOR) & $56(53.5-60)$ & $51.5(47-55)$ & $55(50.5-64)$ & 0.14 \\
\hline $\begin{array}{l}\text { Sex, n (\%) } \\
\text { Female }\end{array}$ & $7(58.3)$ & $7(58.3)$ & $7(58.3)$ & 1.0 \\
\hline $\begin{array}{l}\text { Laterality, n (\%) } \\
\text { Right eye }\end{array}$ & $7(58.3)$ & $6(50)$ & $7(58.3)$ & 0.81 \\
\hline Baseline area $\left(\mathrm{mm}^{2}\right)$ & $58.1 \pm 8.9$ & $56.4 \pm 9.5$ & $57.2 \pm 8.9$ & 0.90 \\
\hline Hemoglobin A1c (\%), median (IOR) & $7.8(6.3-8.3)$ & $8.5(6.5-9.7)$ & $6.7(6.7-6.7)$ & 0.66 \\
\hline Creatinine (mg/dl), median (IOR) & $1.15(0.9-3.3)$ & $0.8(0.7-1.7)$ & $0.8(0.6-1.7)$ & 0.35 \\
\hline $\begin{array}{l}\text { Diagnosis, } \mathrm{n}(\%) \\
\text { Hemovitreous } \\
\text { Tractional retinal detachment }\end{array}$ & $\begin{array}{l}2(16.7) \\
8(66.7)\end{array}$ & $\begin{array}{c}1(8.3) \\
10(83.3)\end{array}$ & $\begin{array}{l}2(16.7) \\
8(66.7)\end{array}$ & 0.73 \\
\hline $\begin{array}{l}\text { Combined tractional and rhegmatogenous } \\
\text { retinal detachment }\end{array}$ & $2(16.7)$ & $1(8.3)$ & $2(16.7)$ & \\
\hline Combined phacovitrectomy surgery, $\mathrm{n}(\%)$ & $9(75)$ & $10(83.3)$ & $10(83.3)$ & 0.55 \\
\hline Use of silicone oil, $\mathrm{n}(\%)$ & $11(91.7)$ & $10(83.3)$ & $11(91.7)$ & 0.71 \\
\hline
\end{tabular}

IQR: interquartile range.

*Kruskal-Walis for quantitative variables and chi-squared for qualitative variables.

Table 2. Daily change in the area of the epithelial defect in the three study groups

\begin{tabular}{|c|c|c|c|c|c|c|c|c|}
\hline $\begin{array}{l}\text { Area in } \mathrm{mm}^{2} \text {, } \\
\text { median (IQR) }\end{array}$ & Baseline & Day 1 & Day 2 & Day 3 & Day 4 & Day 5 & Day 6 & Day 7 \\
\hline Group I & $56.1(51.5-67.5)$ & $36.3(31.2-44.5)$ & $17.1(15.7-20.5)$ & $3.9(2.5-10.5)$ & $0(0-1.1)$ & 0 & 0 & 0 \\
\hline Group II & $51.8(49.9-65.9)$ & $32.1(24.4-43)$ & $12.8(0-19.3)$ & $0(0-3.5)$ & 0 & 0 & 0 & 0 \\
\hline Group III & $56.2(48.9-66.5)$ & $32.2(20.2-46)$ & $9.8(2.6-22.8)$ & $1.5(0-7.1)$ & 0 & 0 & 0 & 0 \\
\hline$p^{*}$ & 0.9326 & 0.4435 & 0.2053 & 0.0530 & 0.3768 & NA & NA & NA \\
\hline
\end{tabular}

NA: not applicable; IQR: interquartile range.

*Kruskal-Walis: comparison of the means of the different groups on the different days.

vitrectomy were included, treated at the Retina and Vitreous Department of the Instituto Mexicano de Oftalmología I.A.P. These patients represent $13.3 \%$ of all pars plana vitrectomies in diabetic patients performed at the institution during the study period. Twelve eyes were included in each treatment group. There were no statistically significant differences between the groups regarding their baseline characteristics (Table 1). Regarding the main objective, the time required for closure of the epithelial defect was $4.25 \pm 0.62$ (range: $3-5$ ), $3.0 \pm 0.85$ (range: $2-4$ ) and $3.33 \pm 0.98$ (range: $2-5$ ) days in groups I, II and III, respectively. In all groups, there was a reduction in the area of the epithelial defect from day 1 , with a smaller area being noted in group II on day 3; however, this difference was not statistically significant compared to the other groups (Table 2 and Fig. 2). All groups had a statistically significant reduction $(p<0.05)$ in the percentage of the epithelial defect area from day 1 , with a $100 \%$ reduction at day 4 in group II and at day 5 in groups I and III. A statistically significant difference $(p<0.05)$ in the percentage of reduction of the epithelial defect area was observed on day 3 between group I $(89.3 \pm 8.3 \%)$ and group II $(97.3 \pm 4.5 \%)$. The re-epithelialization rate was significantly higher in the group that received insulin compared to the patients that received hyaluronate, and also higher in those that received combination therapy compared to those treated with hyaluronate alone. The percentage of re-epithelialization was significantly higher in the group that received insulin than in the group that received hyaluronate (Table 3). No drug adverse effects were reported in either group and no patient was withdrawn from the study or required salvage therapy. 
Table 3. Comparative re-epithelialization and adverse events in the three study groups

\begin{tabular}{|l|c|c|c|c|}
\hline & Group I & Group II & Group III & $\mathrm{p}^{*}$ \\
\hline Reepithelialization rate (mm²/day), median (IOR) & $13.6(12.1-15.8)$ & $18.8(16.5-24.7)$ & $17.5(16.5-21.3)$ & $0.004^{\dagger}$ \\
\hline Percentage of re-epithelialization (\%/day), median (IOR) & $25(20-25)$ & $33.3(25-50)$ & $29.2(25-41.7)$ & $0.008^{\ddagger}$ \\
\hline Adverse effects & 0 & 0 & 0
\end{tabular}

IQR: interquartile range.

*Kruskal-Wallis: comparison of medians in the different groups.

'In the post-hoc analysis, a statistically significant difference was found between groups I and II, and between groups I and III.

${ }^{\ddagger}$ In the post-hoc analysis, a statistically significant difference was found between groups I and II.

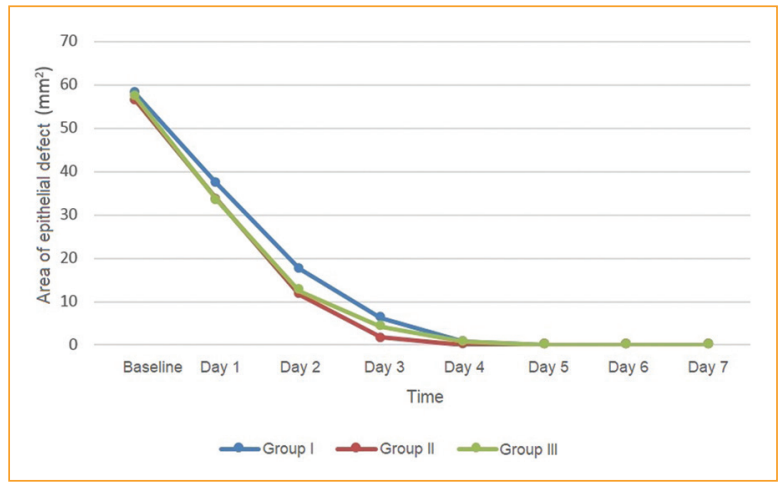

Figure 2. Daily change in the area of the epithelial defect in the three study groups.

\section{Discussion}

Insulin is a peptide closely related to insulin-like growth factor (IGF). In diabetes mellitus, there is a disruption in the insulin signaling pathway, which generates a delay in the healing of corneal wounds and epithelial defects ${ }^{13,14}$. The cellular dysfunction of the cornea in a diabetic patient, together with the failure of tissue repair mechanisms, generates recurrent erosions, delayed healing of corneal defects and ulcers ${ }^{15,16}$. Fragility and inadequate epithelial adherence, accompanied by loss of nerve plexuses and decreased corneal sensitivity, are part of the pathophysiology for the development of diabetic keratopathy ${ }^{17,18}$. Additionally, the loss of nerve growth factor has an important role in epithelial proliferation and migration ${ }^{19}$. Both IGF and substance $P$ have been reported to accelerate corneal epithelial wound healing in diabetic animals ${ }^{20}$. Insulin has been detected in human tears, and the presence of insulin and the IGF1 receptor has been demonstrated on the ocular surface ${ }^{21}$. Topical IGF-1 has been shown to improve corneal epithelial defects, probably by promoting corneal epithelial cell migration and differentiation of stem cells from the limbus ${ }^{22}$. Furthermore, in vitro use of insulin in corneal epithelial cells facilitates the closure of small corneal wounds through optimization of cell migration ${ }^{23}$. Despite these findings, the exact mechanism by which insulin accelerates corneal re-epithelialization in diabetics is not yet fully understood.

In our study, serum creatinine and hemoglobin A1c did not influence corneal re-epithelialization, as previously reported ${ }^{1}$. Most of our patients underwent combined phacovitrectomy (75-83\%); Likewise, $67-83 \%$ had tractional retinal detachment and in $83-92 \%$ silicone oil was used as endotamponade. All this implies greater complexity, prolonged surgical times and a greater probability of performing a corneal debridement to complete the surgery.

The daily change in the area of the epithelial defect showed a significant improvement in the three study groups, with a smaller area and a trend towards a statistically significant difference on the third day favoring the topical insulin group $(p=0.0673)$, while the percentage reduction of the epithelial defect did show a statistically significant difference on day 3 in this group. This is similar to that reported by Fai, et al. ${ }^{7}$, who observed a greater difference at 12 and 60 hours when comparing insulin $0.5 \mathrm{IU} / \mathrm{drop}$ against placebo. Both group II (topical insulin) and group III (combined treatment) had a statistically significant higher corneal re-epithelialization rate compared to group I (sodium hyaluronate), and the percentage of re-epithelialization was significantly higher in the topical insulin group compared to the sodium hyaluronate group.

Ling and Bastion ${ }^{24}$ observed a complete closure of the corneal epithelial defect induced during vitrectomy in diabetics at 64.8 hours (equivalent to 2.7 days) using $0.18 \%$ sodium hyaluronate, compared to 87.6 hours (equivalent to 3.65 days) in diabetics without any topical treatment; likewise, they demonstrated a greater delay until complete re-epithelialization in diabetic patients compared to non-diabetic patients (up to 4 days in diabetics vs. 2.3 days in non-diabetics, both without 
topical treatment). We believe that the differences compared to our findings are due to the small number of patients in both studies, and the follow-up every 24 hours in our study (outpatient management) compared to every 12 hours in their study, which could reflect a certain bias. Similarly, Schulze, et al. ${ }^{25}$ reported longer times for complete closure of the corneal epithelial defect when using other topical treatments in 23 diabetic patients with corneal epithelial debridement during vitrectomy: 4.3 days using autologous serum and 7.1 days using sodium hyaluronate.

The insulin used in this study was Humulin ${ }^{\circledR} \mathrm{R}$, a rapid-acting insulin containing $100 \mathrm{IU}$ recombinant human insulin with excipients such as metacresol, glycerol, phenol, protamine sulfate, zinc oxide, hydrochloric acid, and sodium hydroxide ${ }^{26}$. Despite the fact that many of these excipients are not related to corneal wound healing, it is reported that zinc is involved in skin wound healing ${ }^{27}$. Zinc plays an important role in regulating each phase of the wound healing process, from membrane repair to scar formation, and its systemic deficiency has been linked to refractory corneal defects $^{28}$.

The absence of ocular surface toxicity from insulin in humans was reported in the studies by Bartlett, et al. ${ }^{9,10}$, who showed that insulin at concentrations up to $100 \mathrm{U} / \mathrm{mL}$ (approximately $2.5 \mathrm{IU} / \mathrm{drop}$ ) diluted in saline, did not induce detectable clinical toxicity. Its safety on the ocular surface is also reported with lower doses (0.5-2 IU/drop $)^{7,12}$. Our results are consistent with previous safety findings with a dose of $0.5 \mathrm{IU} / \mathrm{drop}$; however, the presence of excipients such as sodium hydroxide and hydrochloric acid as $\mathrm{pH}$ stabilizers in Humulin ${ }^{\circledR} \mathrm{R}$ could generate changes in the ocular surface that warrant further investigation.

Several limitations of this study should be mentioned, such as the small sample size and the time period between assessments during follow-up (every 24 hours) that did not allow an evaluation of the exact healing rate (in $\mathrm{mm} / \mathrm{h}$ ) of the defect, as patients were not hospitalized. No process was carried out to verify treatment adherence, which was only confirmed verbally by the patient. This is a potential bias since it does not allow to verify whether the treatment was actually completed or not. Another important limitation is the incomplete masking of the treatment, since only the participants were blinded to the treatment but not the researchers, generating a bias that could influence the research results. Additionally, for ethical considerations, we did not include a placebo control group.
Our findings, together with those reported in previous studies in humans ${ }^{7-12}$, show that topical insulin is an effective, safe and easy-to-prepare therapy for the treatment of intraoperative corneal debridement in diabetic patients.

\section{Conclusions}

Treatment with topical insulin $0.5 \mathrm{IU} / \mathrm{drop}$ as monotherapy and combined treatment of insulin with $0.15 \%$ sodium hyaluronate, are effective for the closure of epithelial defects after interaoperative corneal debridement in diabetic patients. The therapy is safe, with no adverse events.

\section{Funding}

The $0.15 \%$ sodium hyaluronate eye drop samples were donated by Théa Laboratories.

\section{Conflicts of interest}

The authors declare no conflicts of interest regarding the formulations used in this study.

\section{Ethical disclosures}

Protection of human and animal subjects. The authors declare that the procedures followed were in accordance with the regulations of the relevant clinical research committee and with those of the Code of Ethics of the World Medical Association (Declaration of Helsinki).

Confidentiality of data. The authors declare that no patient data appear in this article.

Right to privacy and informed consent. The authors have obtained the written informed consent of the patients or subjects mentioned in the article.

\section{References}

1. Hiraoka M, Amano S, Oshika T, Kato S, Hori S. Factors contributing to corneal complications after vitrectomy in diabetic patients. Jpn J Ophthalmol. 2001:45:492-5.

2. Chiang W-Y, Lee J-J, Kuo H-K, Chen Y-H, Chen C-H, Chen Y-J, et al. Factors associated with corneal epithelial defects after pars plana vitrectomy. Int Ophthalmol. 2018;38:105-10.

3. Chen H-F, Yeung L, Yang K-J, Sun C-C. Persistent corneal epithelial defect after pars plana vitrectomy. Retina Phila Pa. 2016;36:148-55.

4. Wang $Y$, Zhou Q, Xie L. [Diabetic keratopathy: new progresses and challenges]. Zhonghua Yan Ke Za Zhi Chin J Ophthalmol. 2014;50:69-72.

5. Matsumura T, Takamura Y, Tomomatsu T, Arimura S, Gozawa M, Takihara $Y$, et al. Changes in matrix metalloproteinases in diabetes patients' tears after vitrectomy and the relationship with corneal epithelial disorder. Invest Ophthalmol Vis Sci. 2015;56:3559-64.

6. Friberg TR, Ohji M, Scherer JJ, Tano Y. Frequency of epithelial debridement during diabetic vitrectomy. Am J Ophthalmol. 2003;135:553-4. 
7. Fai S, Ahem A, Mustapha M, Mohd Noh UK, Bastion M-LC. Randomized controlled trial of topical insulin for healing corneal epithelial defects induced during vitreoretinal surgery in diabetics. Asia-Pac J Ophthalmo Phila Pa. 2017:6:418-24.

8. Zagon IS, Klocek MS, Sassani JW, McLaughlin PJ. Use of topical insulin to normalize corneal epithelial healing in diabetes mellitus. Arch Ophthalmol 2007;125:1082-8.

9. Bartlett JD, Turner-Henson A, Atchison JA, Woolley TW, Pillion DJ. Insulin administration to the eyes of normoglycemic human volunteers. $J$ Ocul Pharmacol. 1994;10:683-90.

10. Bartlett JD, Slusser TG, Turner-Henson A, Singh KP, Atchison JA, Pillion DJ. Toxicity of insulin administered chronically to human eye in vivo. $J$ Ocul Pharmacol. 1994;10:101-7.

11. Wang AL, Weinlander E, Metcalf BM, Barney NP, Gamm DM, Nehls SM, et al. The use of topical insulin to treat refractory neurotrophic corneal ulcers. Cornea. 2017;36:1426-8.

12. Bastion MLC, Ling KP. Topical insulin for healing of diabetic epithelial defects? A retrospective review of corneal debridement during vitreoretinal surgery in Malaysian patients. Med J Malaysia. 2013;68:208-16.

13. Chikama T, Wakuta M, Liu Y, Nishida T. Deviated mechanism of wound healing in diabetic corneas. Cornea. 2007;26:S75-S81.

14. Lutty GA. Effects of diabetes on the eye. Invest Ophthalmol Vis Sci. 2013;54:ORSF81-7.

15. Kaji Y. Prevention of diabetic keratopathy. Br J Ophthalmol. 2005;89:254-5

16. Cisarik-Fredenburg P. Discoveries in research on diabetic keratopathy. Optometry. 2001;72:691-704.

17. Zhivov A, Winter K, Hovakimyan M. Imaging and quantification of subbasal nerve plexus in healthy volunteers and diabetic patients with or without retinopathy. PLoS One. 2013;8:e52157.

18. Midena E, Brugin E, Ghirlando A, Sommavilla M, Avogaro A. Corneal diabetic neuropathy: a confocal microscopy study. J Refract Surg . 2006;22:S1047-52.
19. Saito J, Enoki M, Hara M, Morishige N, Chikama T, Nishida T. Correlation of corneal sensation, but not of basal or reflex tear secretion, with the stage of diabetic retinopathy. Cornea. 2003;22:15-8.

20. Akamura M, Kawahara M, Morishige N, Chikama T, Nakata K, Nishida T. Promotion of corneal epithelial wound healing in diabetic rats by the combination of a substance P-derived peptide (FGLM-NH2) and insulin-like growth factor-1. Diabetologia. 2003;46:839-42.

21. Rocha EM, Cunha DA, Carneiro EM, Boschero AC, Saad MJA, Velloso LA Identification of insulin in the tear film and insulin receptor and IGF-1 receptor on the human ocular surface. Invest Ophthalmol Vis Sci. 2002;43:963-7.

22. Wirostko B, Rafii M, Sullivan DA, Morelli J Ding J. Novel therapy to treat corneal epithelial defects: a hypothesis with growth hormone. Ocul Surf. 2015;13:204-12.e1.

23. Shanley LJ, McCaig CD, Forrester JV, Zhao M. Insulin, not leptin, promotes in vitro cell migration to heal monolayer wounds in human corneal epithelium. Invest Ophthalmol Vis Sci. 2004;45:1088-94.

24. Ling K, Bastion M-LC. Use of commercially available sodium hyaluronate $0.18 \%$ eye drops for corneal epithelial healing in diabetic patients. Int Ophthalmol. 2019;39:2195-203.

25. Schulze SD, Sekundo W, Kroll P. Autologous serum for the treatment of corneal epithelial abrasions in diabetic patients undergoing vitrectomy. Am J Ophthalmol. 2006;142:207-11.

26. Patient information for Humulin R 100IU/ml. Eli Lilly and Company; 2019. (Consultado en septiembre de 2020.) Disponible en: http://pi.lilly.com/us/ humulin-r-ppi.pdf

27. Lansdown AB, Mitrastschijski U, Stubbs N, Scanlon E, Agren MS. Zinc in wound healing: theoretical, experimental and clinical aspects. Wound Repair Regen. 2007:15:2-16.

28. Tokumitsu A, Kusunoki Y, Torii K. Refractory corneal epithelial diseases due to zinc deficiency: clinical features and treatment in patients with severe motor and intellectual disabilities. Biomedical Research on Trace Elements. 2020;31:1-5. 